\title{
Analysis of the impact of socio-economic problems in rural area on agricultural education
}

\author{
E.Yu. Astrakhantseva* \\ FSBEI HE Moscow State University of Food Production, Moscow, Russia
}

\begin{abstract}
The article evaluates the results of scientific research on the specific features of the formation of qualified labor resources in the agricultural sector. The results of the study conducted by a group of experts from the Ministry of Agriculture of Russia and the SRI Higher School of Economics with the participation of the author in 2017 are compared with the results of similar studies in the period 2018-2020. The article reveals the existing close relationship between social problems in rural areas and the lack of interest in graduates of specialized agricultural higher educational institutions in job placement in their specialty. The work analyzes the negative impact of short industrial practice of students on the agricultural education quality and assesses the consequences of the lack of a modern technological base for conducting practical training in many higher educational institutions, which leads to the unreadiness of graduates for independent work. The possible ways of finding a balance of interests between the regional administration, higher agricultural educational institution, students and business are considered on the example of the activities of the Omsk State Agrarian University named after P.A. Stolypin. The article also highlights the problems in the field of education and obtaining new competencies faced by representatives of peasant (farm) households. In conclusion, proposals are made to solve the urgent problems of agricultural education. Basic provisions: - the job placement of graduates of higher educational institutions in agricultural enterprises is negatively affected by the social problems of the village; - graduates of agricultural universities do not meet the expectations of employers, as educational institutions do not provide sufficient practical knowledge and skills due to the lack of orientation for the practical activities of future specialists; - for representatives of peasant (farm) households, distance education forms and the availability of highly qualified consultants in the field of digital technologies and product promotion are necessary.
\end{abstract}

\section{Introduction}

In agriculture of the Russian Federation, despite the growth of production volumes and successful overall development, there is a whole range of problems and tasks, among which the most urgent are ensuring employment and income of the rural population. These problems

\footnotetext{
* Corresponding author: astra31@gmail.com
} 
are acute for young people who are just choosing a life path, and for young specialists who have already received specialized agricultural education.

When considering the organization and quality of agricultural education, it should be recognized that they are closely related to the social problems of rural residents. The lack of jobs, low wages, difficult work conditions, low level of household comfort are the reason for the migration of the population to the cities and the refusal of many young professionals to live and work in rural areas.

\section{Research methods}

The research is based on the use of dialectical, logical, and comparative methods. The information base is the data of the Goskomstat (Federal Public Statistics Service), the materials of a number of documented and published surveys in scientific journals, as well as the data of the research carried out with the participation of the author to develop the directions of priority development of the Russian agro-industrial complex by the Ministry of Agriculture of Russia together with the SRI Higher School of Economics, on the basis of which the "Forecast of scientific and technological development of the Russian agroindustrial complex for the period up to 2030" was developed [1, 2, 3].

\section{Research results}

The works of many foreign and Russian authors are devoted to the formation of qualified personnel. Agricultural education issues are discussed in the publications of the staff of the UN Food and Agriculture Organization (FAO) [4, 5]. Agricultural education issues are particularly acute for developing countries and this is reflected in numerous publications on the problems of training in Latin America, Africa and Asia [6, 7, 8]. Moreover, it should be noted that not only issues related to higher agricultural education are being studied, but also the training of small farmers [9]. In developed countries with an industrial agriculture, the training of agricultural specialists is part of the programs of national Ministries of Agriculture. In this way, in the United States, one of the institutes within the Department of Agriculture (USDA) is engaged in educational programs (National Institute of Food and Agriculture - United States Department of Agriculture) [10]. Programs of study in the United States include all areas related to agriculture, biotechnology - students at American universities can choose a field of study from more than 30 specialties in the agri-food sector. In addition to teaching, educational institutions are engaged in research and have high-quality high-tech laboratory and training facilities. The leading US universities that have agricultural institutes in their structure include the College of Agriculture of Cornell University, the University of Georgia, the College of Agricultural Sciences of the University of Florida and a number of others.

The situation in Russia differs both from developing countries, where the problem of poverty is much more acute and the number of people employed in agriculture is high, and from developed countries, where there is no such deep difference in the quality of life and income level of those living in rural areas and cities.

In 2017, a group of experts with the participation of the author conducted a survey (in a questionnaire survey, which was about 1,000 people from rural residents of the Central region participated. The main objective of the questionnaire survey was to assess the population's satisfaction with the quality of life in rural areas of Russia. The main purpose of the study was to analyze the influence of living conditions and employment on the formation of personnel in agricultural production. It showed that the most sensitive problems for the 
village residents were low wages, unemployment, poor roads and lack of necessary medical care. The survey revealed the relative inertia of village residents - no more than $17 \%$ of respondents at that time were ready to consider moving to the cities, but only half of the respondents expressed a desire for their children to continue living in rural areas. A significant part of the respondents noted the deterioration of employment conditions: lower wages, reduced social benefits and employment opportunities.

The answers showed that the most attractive aspects of rural life are the ability to run a personal farm, the consumption of organic food, a healthy lifestyle and proximity to nature.

Even such a small research, conducted in a limited number of localities, revealed the characteristics of employment in agriculture, which significantly affect the needs for knowledge and skills that can be obtained through the education system. The first and main feature is the multistructurality that exists within the same locality. In this way, in one village, personal subsidiary farms, peasant (farm) households and a branch of a large agricultural enterprise can coexist. The forms of use of labor resources in them differ significantly - wage labor in organizations and self-employment in other types of farms. The motivation also differs. Heads of peasant (farm) households and owners of personal subsidiary farms cannot stop production, even if market conditions and weather conditions make it unprofitable.

Over the past 4 years, the share of the rural population has decreased slightly (by $0.4 \%$ ). In $2020,25.3 \%$ of the Russian population lived in rural areas [11].

Studies conducted in 2018-2020 by other authors have shown that the situation in rural areas is not improving and problems with the training of labor resources are not systematically solved. It should be noted that the social and material conditions of living and working differ not only in urban and rural areas: in rural localities near district and regional centers, they are better than in remote villages and rural settlements. In general, rural life is hard work with seasonal peaks of loads, uncomfortable living conditions, poor roads, lack of accessible social infrastructure in the form of medical and educational institutions, catering enterprises, cinemas, theaters and other benefits of the city. The average salary in rural areas does not exceed $56 \%$ compared to the national average [12]. As a result, the share of the rural population is declining due to both natural decline and migration. At the same time, a further decline in the share of the rural population and, accordingly, the labor force is predicted [12].

In these conditions, education for rural residents plays the role of a "social elevator", which allows not only to move up the social ladder, but also to change the living conditions.

The survey of students of the Novosibirsk State Agrarian University, conducted by I. G. Kuznetsova in 2020 [13], showed an increased mobility of the rural population. Despite the fact that $61 \%$ of the students she interviewed lived in rural areas, only $18 \%$ of them answered that they deliberately chose a specialty and plan to work in agriculture, $37 \%$ reported that the chosen specialty generally corresponds to their interests, $13 \%$ chose a specialty because they considered the prospects favorable for employment; $22 \%$ said that the main motive for choosing a specialty was free education, and $10 \%$ reported that their admission to this university was the result of advice from relatives or an accident. From the responses received, it follows that no more than $55 \%$ of the last-year students surveyed seriously consider the prospect of employment in agricultural enterprises after graduation. However, the author of the study included in the questionnaire a question about the priorities of choosing a job if the working conditions and wages are identical in both urban and rural areas. $68 \%$ of students answered that they would choose to work in the city, $9 \%$ did not give an answer and 23\% confirmed that they are ready to work in the countryside. This coincides with the real statistics - only $20 \%$ of graduates of agricultural universities work in their specialty.

The students' answers to the question of what factors are most important for them when choosing an urban employment option are of interest. The answers were divided between the advantages in the household plan (38\%), the availability of cultural centers $(24 \%)$, the 
possibility of self-realization (21\%) and the receipt of further quality education $(27 \%$, the interviewed students could choose several items from the answer options).

Those who chose rural life have different priorities - living in nature (56\%), the opportunity to have a private farm (35\%), a quiet lifestyle (36\%), environmentally friendly food $(31 \%)$. If we compare these data with the results of the 2017 study with the participation of the author, it can be noted that the motives of those who choose to live in rural areas have not changed, and the goals of those who want to have a comfortable life and social sphere, good employment prospects and higher wages have become more deterministic.

This is not the only modern study devoted to the problems of professional orientation, the choice of place of residence and the type of employment of rural youth. But it accurately describes the main problem of the village: non-compliance of working and living conditions with the life priorities of young people receiving specialized agricultural education.

The conclusion is disappointing in the life priorities significantly outweighing the interest in the chosen specialty, which means that the expensive resources and time spent on education by the state and the students themselves, from the point of view of staffing agriculture, are wasted. There is no simple solution for this problem.

Turning to the analysis of the situation with the personnel training for agriculture, it should be noted that different groups of agricultural producers have different needs for personnel and their qualification level. But most university programs are designed for largescale industrial production. At the same time, all agricultural producers are experiencing a shortage of qualified personnel. According to the All-Russian Agricultural Census of 2016, less than $50 \%$ of the heads of agricultural organizations had a higher agricultural education, table 1 .

Table 1. Indicators of education level of heads of agricultural organizations according to the results of the All-Russian Agricultural Census of 2016, in \% of the total number

\begin{tabular}{|c|c|c|c|c|c|c|}
\hline & \multicolumn{2}{|c|}{$\begin{array}{c}\text { Higher professional } \\
\text { education }\end{array}$} & \multicolumn{2}{|c|}{$\begin{array}{c}\text { Secondary professional } \\
\text { education }\end{array}$} & $\begin{array}{c}\text { Primary } \\
\text { vocational } \\
\text { education }\end{array}$ & $\begin{array}{c}\text { secondary } \\
\text { (complete) } \\
\text { general } \\
\text { education }\end{array}$ \\
\hline RF & 77.1 & Total & Total & $\begin{array}{c}\text { incl. } \\
\text { agriculture }\end{array}$ & & 3.5 \\
\hline
\end{tabular}

Source: data from the EMISS website

Researchers and experts in the field of higher agricultural education - Butyrin V.V., Butyrina Yu.A., Chernenko E.V. [14], Romanyuk M.A., Sukharnikova M.A., Chekmareva N.V. [15] - note the main problems in its organization.

Some of these problems are called "chronic" by researchers, and their roots go back to the period of Russian reforms in the 90s of the XX century, when there was a gap between education and production, as well as scientific institutions. Agricultural educational institutions gradually lost contact with agricultural enterprises as customers of personnel and largely became part of the system of the Ministry of Education and Science, which ultimately led to an imbalance between the number of graduates of regional educational institutions in certain specialties and the real needs for them.

As a result, in agriculture, as the authors of the study [3] note, "the average age of working specialists is more than 50 years and there is no adequate replacement for them."

The quality of agricultural education suffers from the lack of practical knowledge and skills received by graduates. Moreover, according to experts [13], the quality of practical training is declining against the background of increasing requirements for the qualifications of graduates and agriculture digitalization. The lack of experience makes graduates "blanks" for employers who are forced to do work for an educational institution and train specialists in the skills they need. At this stage, with a 4-year period of training in agricultural specialties 
in higher educational institutions, there is clearly not enough time for practice (no more than three weeks for production practice), and the practice itself is, as a rule, of a formal nature of familiarization with production and its managers.

There is a clear need to organize practical training on the basis of real production and for a longer period with the protection of the results for the type of cases and with the mandatory publication of the results of the work performed in electronic publications.

The bases for training practice are also an organizational and financial problem. Not all higher educational institutions have educational facilities, and the level of their technical equipment does not correspond to modern production technologies.

It is obvious that the problem of choosing partners interested in high-quality education for agricultural universities requires the joint work of all interested parties: educational institutions, agricultural and processing companies, the Ministry of Education and Science of the Russian Federation, the Ministry of Agriculture of Russia, regional and municipal authorities and students themselves. There is a positive experience of such cooperation in a number of universities and it should be used in the regions.

There is also the problem of high-quality teaching staff of universities, the lag of teacher qualifications from the needs of high-tech modern agriculture.

Nevertheless, all the above problems have already been solved in some regions of Russia. An example of the transformation of agricultural education is the activity of the FSBEI HE Omsk State Agrarian University n.a. P.A. Stolypin. The government of the Omsk region has decided to create an agricultural technological industrial cluster, in which the Omsk University serves as the main multidisciplinary information and consulting center by teachers and students. The University has managed to unite a large number of interested persons - its teachers and students, representatives of business, government agencies. The organization of competitions of student works, conferences and master classes is carried out jointly with the largest regional companies-employers - "Omsk Bacon" OJSC, "Agrarian Group" OJSC. Students learn the skills of participating in scientific works, and the authors of the most interesting and significant works receive personalized scholarships and invitations from future employers. It should be noted that Omsk University has managed to keep the departments in production and this ensures the applied nature of training. The most valuable thing in the activities of the Omsk University is a direct dialogue with representatives of agribusiness on the formation of educational programs. Exactly this scheme allows graduates to gain the necessary practical skills and become specialists who are able to work independently immediately after graduation from a higher educational institution. The interaction of teachers, students and business takes place within the framework of "public professional councils", and each faculty has its own council.

In 2020, Omsk University expanded its cooperation with business and created a new "Digital Situation Center", which activities are dedicated to solving the problems of digitalization in all sectors of agriculture and ecology. The new Center attracted the largest regional companies as partners and employers - "KZ Rostselmash" LLC, "Soyuz Agro" LLC, "Dairy Systems" LLC, peasant farm "Triticum" and several others.

In the organization of the educational process at Omsk University, digital technologies are used, including the use of virtual versions of enterprises with daily updated operational data and a management accounting system that allows to make decisions. In fact, this means that students in the learning process solve professional problems on real material. But this valuable positive experience is not systematic and is the result of a special close relationship between the administration of the Omsk region, the rector of the University and the business community.

The use of digital technologies in the learning process and during the internship is a significant advantage. There is a rapid process of re-equipping the production of agricultural 
digital equipment, satellite navigation systems - GPS, GLONASS and the corresponding software.

In 2019, the Ministry of Agriculture of Russia launched the project "Digital Agriculture", the main goal of which is "transformation of agriculture through the introduction of digital technologies and platform solutions to ensure a technological breakthrough in the agroindustrial complex and achieve productivity growth in "digital" agricultural enterprises" [16]. Moreover, the project provides for a 2 -fold increase in labor productivity and training of personnel - in 2024, 50\% of all specialists employed in agriculture should have the appropriate competencies.

Returning to the topic of cooperation between state bodies, educational agricultural institutions and business, it should be noted that universities do not always successfully solve the problems of establishing relations with the government, the Ministry of Education and local business.

The demand for specialists exists not only in large agricultural enterprises, but also in medium and small agribusiness and peasant (farm) households. It should be noted that the issues of providing personnel for peasant (farm) households (hereinafter referred to as $\mathrm{P}(\mathrm{F}) \mathrm{H}$ ) have been studied much less fully than for agricultural organizations.

There are few studies devoted to the personnel needs of $\mathrm{P}(\mathrm{F}) \mathrm{H}$. One of them was held in 2019 by M.G. Leshcheva [17] among the farmers of the Stavropol Krai, where the role of farmers in providing food to the region is quite large. In this way, in 2018 , farmers produced more than $27 \%$ of vegetables, $20 \%$ of cereals, $14 \%$ of potatoes and $9 \%$ of milk.

The research of M.G. Leshcheva showed that the absolute majority of the heads of $\mathrm{P}(\mathrm{F}) \mathrm{H}$ are men ( $79 \%$ of all respondents) over 45 years old, and $65 \%$ of them have worked in agriculture for more than 30 years and were mostly heads of agricultural organizations. They do not have time for systematic training and professional development - more than $70 \%$ of respondents, having become heads of households, have never engaged in professional development. Less than a quarter of the respondents $(22 \%)$ took some courses or seminars, but more than 5 years ago.

Farmers can not engage in their professional self-education due to too busy schedule, lack of free time. But they also do not have information about where and how they can get additional education. At the same time, they believe that they need it, because they do not have knowledge of how to promote their products on the market and receive state support the lack of such information was noted by $55 \%$ of the surveyed heads of $\mathrm{P}(\mathrm{F}) \mathrm{H}$.

As compensation, they extensively use the Internet to obtain non-system information in the areas they need. At the same time, more than $70 \%$ of the $\mathrm{P}(\mathrm{F}) \mathrm{H}$ farm heads said that they would like to improve their professional level in order to increase the scale of activities, use digital technologies and transition to ecological organic agriculture. The priority forms for most heads of households are distance learning or information and consulting services. Among the necessary new competencies, the heads of $\mathrm{P}(\mathrm{F}) \mathrm{H}$ highlighted, first, the skills of using GLONASS-based navigation tools and processing arrays of electronic data on the phytosanitary and epizootic situation and on hydrometeorological conditions.

Representatives of $\mathrm{P}(\mathrm{F}) \mathrm{H}$, as well as the student audience, and residents of rural areas in 2017 confirmed that the necessary conditions for attracting qualified workers to agriculture are good living conditions in rural areas $-82 \%$ of respondents associated migration with difficult living and working conditions, while $44 \%$ also considered it necessary to develop Internet networks in rural areas.

It should be noted that those who took part in this survey are successful agricultural entrepreneurs. Heads of large $\mathrm{P}(\mathrm{F}) \mathrm{H}$ are already using a whole range of digital technologies. They do not see the future in the use of low-skilled labor, they need the advice of highly qualified specialists who simultaneously have knowledge of digital technologies and 
agriculture. The problem is that there are very few such specialists in the labor market not only in the Stavropol Krai, but also in the entire Russian Federation.

\section{Conclusions}

Personnel policy and training in agriculture is not inferior in importance to the technical and technological equipment of the industry. The availability of qualified personnel is one of the main conditions for ensuring food security and forming highly competitive position of the Russian Federation in the world market of agricultural products.

The consolidation of young specialists in agriculture cannot be successful without solving social and economic problems: creating jobs, obtaining a level of wages comparable to the national average, the availability and accessibility of social infrastructure, housing with an acceptable level of living comfort. This requires considerable details of existing programs, financial participation of business and the state, and the creation of new partnership mechanisms for the development of rural settlements.

In addition to solving the general tasks listed above, there is a need to reform the existing system of agricultural higher education, provide a high-tech base for practice, increase practice duration, improve the skills of the teaching staff of agricultural universities and organize close ties with agricultural producers and processors. This will require finding a balance between the requirements of the Ministry of Education and Science of the Russian Federation and the interests of agricultural universities and agricultural businesses (customers of services). Agricultural universities (industry-specific) should be focused on the customers of their services, that is, on training personnel for large, medium and small agribusiness and peasant (farm) households. To do this, their training programs should take into account current trends/directions of the agro-industrial complex development. To keep up with the times, ideally - to be proactive. The Ministry of Science and Higher Education of the Russian Federation should take this into account when accrediting new programs and training areas, as well as when adjusting old ones.

Considering the high rate of digitalization of agriculture, it is advisable not only to provide mechanisms and goals for the introduction of digital technologies, but also to conduct research on the medium and long-term consequences of their impact on the social and economic conditions of employment and life of the rural population.

\section{References}

1. Forecast of scientific and technological development of the agro-industrial complex of the Russian Federation for the period until 2030, URL: http://biotech2030.ru/prognoznauchno-tehnologicheskogo-razvitiya-agropromyshlennogo-kompleksa-rossijskojfederatsii-na-period-do-2030-goda/

2. E. Astrakhantseva, Priorities for the development of the Russian agro-industrial complex through the prism of the Strategy of Scientific and Technological Development of the Russian Federation, URL: https://docplayer.ru/71034708-Prioritety-razvitiya-apkrossii-cherez-federacii-e-yu-astrahanceva-zamestitel-ministra-selskogo-hozyaystvarossiyskoy-federacii.html

3. Strategy for the development of agricultural education in the Russian Federation until 2030, URL:https://www.bashkortostan.ru/presscenter/news/18530/

4. E. Burton, Swanson Robert P. Bentz Andrew J. Sofranko, Improving agricultural extension, (1998) http://www.fao.org/3/W5830E/w5830e0h.htm 
5. Introducing the farm business school. A training package. Food and Agriculture Organization of the United Nations. Rome, (2015) http://www.fao.org/3/i4565e/i4565e.pdf

6. T. Brown, S. Majumdar, Agricultural TVET in developing economies: Challenges and possibilities. URL:https://unevoc.unesco.org/pub/discussion_paper_agricultural_tvet.p df

7. Agricultural education and training access barriers report, URL: https://www.nda.agric.za/doadev/sidemenu/educationandtraining/aet_access_barriers_t o_aet.pdf

8. Workforce, Training and Skills Issues in Agriculture/ A report to the Primary Industries Ministerial Council by the Industries Development Committee Workforce, Training and Skills Working Group October 2009 https://citeseerx.ist.psu.edu/viewdoc/downl oad?doi=10.1.1.462.946\&rep $=$ rep1\&type $=$ pdf

9. Farm Employee Training Resources and Standard Operating Procedures. URL: https://smallfarms.cornell.edu/resources/farm-employee-training-resources-andstandard-operating-procedures/

10. U.S. Department of Agriculture (USDA) website URL: https://nifa.usda.gov

11. Goskomstat (Federal Public Statistics Service) website. URL: https://showdata.gks.ru/report/278932/. Access date 04.05.2021.

12. A.N. Semin, E.G. Skvortsova,Economics of Agriculture, 4, 50-55 (2020)

13. I.G. Kuznetsova, Economics of Agriculture, 1 (2021)

14. V.V. Butyrin, Yu.A. Butyrina, E.V. Chernenko, Economics of Agriculture, 12, 23-28, (2020)

15. M.A. Romanyuk, M.A. Sukharnikova, N.V. Chekmareva, Economics of agriculture, 7, 35-40 (2020).

16. Departmental project "Digital Agriculture".

URL: https://mcx.gov.ru/upload/iblock/900/900863fae06c026826a9ee43e124d058.pdf. Access date 04.05.2021.

17. I.G. Leshcheva, Economics of Agriculture, 4, 33-38 (2020) 